\title{
GCU
}

Glasgow Caledonian

University

University for the Common Good

\section{Working in the field of complex psychological trauma: a framework for personal and professional growth, training, and supervision}

Coleman, Anne Marie; Chouliara, Zoe; Currie, Kay

Published in:

Journal of Interpersonal Violence

DOI:

$10.1177 / 0886260518759062$

Publication date:

2021

Document Version

Author accepted manuscript

Link to publication in ResearchOnline

Citation for published version (Harvard):

Coleman, AM, Chouliara, Z \& Currie, K 2021, 'Working in the field of complex psychological trauma: a

framework for personal and professional growth, training, and supervision', Journal of Interpersonal Violence, vol. 36, no. 5-6, pp. 2791-2815. https://doi.org/10.1177/0886260518759062

\section{General rights}

Copyright and moral rights for the publications made accessible in the public portal are retained by the authors and/or other copyright owners and it is a condition of accessing publications that users recognise and abide by the legal requirements associated with these rights.

Take down policy

If you believe that this document breaches copyright please view our takedown policy at https://edshare.gcu.ac.uk/id/eprint/5179 for details of how to contact us. 


\begin{abstract}
To Explore the positive and negative impacts of working therapeutically in Complex Psychological Trauma (CPT), particularly the field of Gender Based Violence (GBV) and Childhood Sexual Abuse (CSA) from the clinicians' perspective. The focus was on the prospect of positive gains and growth for therapists. Twenty-one clinicians $(n=21)$ (counsellors/psychotherapists and psychologists) from National Health Service (NHS) specialist trauma services, a community mental health team, and specialist sexual assault counselling organisation participated. Interpretative Phenomenological Analysis (IPA) was utilised to conduct single one-off interviews and analysis. Six themes were identified: Called to the work; Connection, separation and oneness; In to and out of the darkness; Chaos into meaning; Reparation not repetition; and Expansion and growth. The first 'Therapist Led Framework of Growth in Trauma Work' is presented. Vicarious Post Traumatic Growth (VPTG) was a key finding, with CPT therapists experiencing a 'challenge/benefit/change' growth process. Adoption of actively relational strategies to enhance clinicians' growth process through trauma work is being proposed. The benefits of conceptualising both the positive and negative impacts of such work for supervision, training, shaping the formal curricula, service management, and CPD are being discussed. The need for good practice guidelines on self-care internationally is highlighted.
\end{abstract}

\title{
Keywords
}

complex psychological trauma, gender based violence, vicarious traumatisation, vicarious post traumatic growth, childhood sexual abuse

\section{Findings}


- Adopting a positive growth mind-set in all stages of training, practice, service provision, and supervision in CPT work is good practice for clinician and patient safety and quality of care.

- While therapists in CPT (including GBV and CSA) work often face extra personal and professional challenges, they also experience a previously unrecognised growth process.

- A growth based, as opposed to a deficiency-based, framework is likely to be more empowering for clinicians working with CPT. 


\section{Introduction}

Complex psychological trauma (CPT) occurs as a result of repetitive, prolonged trauma involving harm or abandonment by a caregiver or other interpersonal relationships with an uneven power dynamic (Stein et al., 2016). It is associated with sexual, emotional or physical abuse or neglect in childhood, childhood sexual abuse (CSA), intimate partner violence, kidnapping and hostage situations, indentured servants, prisoners of war, bullying, concentration camp survivors, and defectors of cults or cult-like organizations. Complex psychological trauma therefore is relational in nature with long-lasting impact (Courtois \& Ford, 2009). Complex posttraumatic stress disorder (CPTSD) was originally proposed by Herman (1992a) to describe a syndrome observed in survivors of prolonged and repeated trauma. Recent evidence (Cloitre et al., 2013) supports complex trauma as a clinical entity. CPTSD is now included in the International Classification of Diseases (ICD) as a diagnosis (Karatzias et al., 2016). The forthcoming ICD-11 will include a diagnosis of CPTSD describing six distinct symptoms of posttraumatic stress disorder (PTSD) plus an additional set of symptoms that reflect Disturbances in Self Organization (DSO), (Karatzias et al., 2017).

Complex Psychological Trauma consists of diverse clusters of symptoms, including alterations in affect regulation, consciousness, sense of self, perception of the perpetrator, relations with others, and systems of meaning (Resick, P.A. et al 2012). It is much wider than just post traumatic stress disorder (PTSD) exactly because of its relational and long-lasting nature and impact (Courtois \& Ford, 2009). Nevertheless, there is high comorbidity and overlapped between CPT, PTSD, borderline personality disorder and substance abuse disorders, as shown by recent research (Ford et al., 2007).

Exposure to psychological trauma in general is very prevalent (Benjet et al., 2016; Roberts et al., 2011). Most people experience trauma in various forms during their lives (Ogle et al. 
2014; Cook et al., 2011; Norris \& Sloan, 2007; Breslau et al., 1998; Kessler et al., 1995) resulting for some in experiencing psychological trauma symptoms. Prevalence of complex trauma is hard to identify, because of the wide range of traumas it encapsulates. It is believed that actual prevalence of CPT is much higher than recorded due to under-reporting, due to the often stigmatising nature of such traumas. The frequency of one type of CPT, i.e. CSA, alone is high. Childhood sexual abuse is a global problem with one meta-analysis combining figures for CSA from more than 200 publications (including 331 independent samples with a total of 9,911,748 participants) estimating a prevalence of $127 / 1000$ (Stoltenborgh et al 2011). Within the UK it is suggested that 1 in 20 children in the UK have been sexually abused (Radford et al., 2011) and over 3,000 children were identified as needing protection from sexual abuse in 2014 (Child protection register and plan statistics for all UK nations for 2014). Furthermore, the prevalence of CPT is expected to increase, especially because of exposure to war, conflict, extreme weather conditions and other extreme circumstances (UKPTS 2016) with dissociation, interpersonal functioning and affect regulation being significantly affected (Hinton and Lewis-Fernandez 2011; Morina and Ford 2008). More broadly, exposure to childhood maltreatment (including CSA, physical and emotional abuse and neglect) has been identified for males and females as a significant risk factor for anxiety and depressive disorders, bringing a financial as well as a mental health burden (Moore et al 2015). It is thought that the maltreatment of children has been found to impair their current and future health in every country and cultural context in which it has been investigated, with an increase in human anguish and economic costs (Fang et al 2015).

Complex trauma tends to have a significant impact on psychological and physical health of survivors and on their use of services (World Health Organisation, 2014, United Nations 2013). In specific, child sexual abuse (CSA) alone is a major cause of poor mental health, 
functional disability, high utilization of health services, and a variety of physical problems, including headaches, gynaecological and gastrointestinal symptoms, asthma, functional impairment, and poor subjective health both in childhood and in adulthood (Spataro et al., 2004; Leserman, 2005; Cohen et al., 2008). Complex trauma is associated with various psychological challenges, including mood disorders, anxiety, substance disorders (Molnar et al., 2001), marriage and family problems (Dube et al., 2005) and can be a cause of serious psychiatric problems in childhood and in adulthood (Spataro at al., 2004; Teicher \& Parigger, 2015). Complex trauma has a severe impact on health resources too. CSA alone costs the UK $£ 3.2 \mathrm{bn}$ a year, terms of costs for health, criminal justice service, services for children and loss of productivity to society in adulthood (Saied-Tessier, 2014). Annual healthcare costs worldwide were found to be significantly higher for those who suffered complex traumas. Extra costs ranged across mental health, emergency admissions, outpatient and pharmacy, primary and specialist care (Rovi et al., 2004). Complex trauma has profound mental and physical health consequences and is associated with staggering long-term economic costs across the lifespan, rendering lack of action very costly (Thielen et al., 2016).

The increased prevalence of psychological trauma and the consequent growing needs for support for such clients mean that more and more clinicians will be working with these issues and therefore will be exposed to the demands of providing such services. In fact, working clinically with complex trauma is shown to being personally and relationally demanding on clinicians and thus having a significant impact on them, as compared to non-fragile process (Figley, 2002a, 2002b; Tedeschi \& Calhoun, 2004; Hernández et al.,2007; Staub \& Vollhardt, 2008). Risk for vicarious traumatisation is actually higher in those working therapeutically with complex trauma. Exact prevalence of vicarious traumatisation, burnout and compassion fatigue in clinicians working within the field of complex trauma is hard to identify because of 
differences across countries and settings, differences in definitions and challenges in reporting (Chouliara et al. 2008).

Given the increasing prevalence of such traumas and the potential impacts, clinicians will need to be appropriately equipped and supported to deal with the associated challenges. There is some generic research on the experience of clinicians working with trauma. However, little is known about the impact of complex/relational trauma, and GBV and CSA work in particular, so far, especially from a clinician perspective. Even less is known about the whole range of experience and impact from working in this field, including the impact on selfdevelopment and growth as well as the challenges. Nevertheless, understanding the experience and challenges from a clinician perspective is crucial if we are to select, train, support, and supervise clinicians appropriately for this type of work. This will also safeguard patient safety, engagement with psychological therapy, and satisfaction with services. We do know from previous work that patient satisfaction, engagement with treatment and better management of drop outs are also closely related with competent therapists who are knowledgeable about trauma and can establish and maintain effective therapeutic relationships with clients with complex trauma (Chouliara et al., 2011, 2012; 2013; 2017; Chouliara \& Narang, 2017), In fact the quality of the therapeutic relationship is a key factor of treatment effectiveness and engagement irrespective of therapeutic allegiance (Horvath, A.O. \& Symonds, B.D., 1991). If clinicians have to maintain such therapeutic relationships, the demands on their self care, personal and professional developing as well-meaning making processes will be great and such needs have to be addressed. There is actually very little in the formal curriculum of clinicians on complex trauma in the UK. In addition, the literature so far has predominantly focused on the negative impact of CPT work on clinicians, especially regarding vicarious traumatisation. (Adams et al, 2006: Baird \& Kracen, 2006: Bride, 2007: Canfield 2005: Shah et al, 2007: Smith, 2007: Sprang et al., 2007). Therefore, 
research that provides an overview of the whole process including challenges and benefits from this work is both timely and justified.

\begin{abstract}
Aims \& Objectives
The objective of the present study is to understand the impacts on clinicians of working in the field of complex psychological trauma. This will be achieved by aiming at identifying potential challenges as well as positive growth from a clinician point of view; and also in developing a clinically applicable framework that best 'fits' these perspectives.
\end{abstract}

\begin{abstract}
Method
Interpretative Phenomenological Analysis (IPA) was selected as the most appropriate qualitative approach to explore the clinicians' lived experience of CPT work. (Smith et al., 2009). The flexibility of the approach, where it is possible to engage with both new areas, and to work within existing theoretical frameworks (Reid et al., 2005) allowing for creativity and freedom (Willig, 2001) makes it of particular value to healthcare research generally (Pringle et al., 2011), and to this research in particular. In addition, the sensitive and personal nature of this enquiry makes IPA a very good 'fit' for the topic and population (Smith, 2009).
\end{abstract}

\title{
Participants
}

Purposeful sampling was utilised to invite therapists (recruited via the researcher's own professional network) from within specialist trauma services and specialist sexual assault counselling organisations, in order to identify those likely to offer data relevant to both the research goals and to the methodology (Finlay \& Ballinger, 2006). A total of 48 clinicians were invited and 21 participants were finally recruited from mental health teams within the NHS, including Psychology, Psychotherapy/Counselling, and Occupational Therapy, 
professionals. The aim was to select interviewees with a background of working in the field of CPT, including (but not limited to) GBV/CSA. All participants were currently working with clients presenting with CPT. Clinicians gave written informed consent to participate in face to face interviews. These took place within the lead author's own workplace, in either a private office space or clinical room, over a period of four months within 2014.

The sample was consisted of 17 females and 4 males. 6 participants interviewees being were aged between 30-39 years old, 6 were aged between 50-59, and 9 between 40-49 years old. In terms of clinical experience in this field, the majority were clinicians with significant in CPT/GBV with all having had a minimum of 2 years' involvement (1 therapist), 7 with 35years, 8 with 6-15 years and 5 participants having worked in this area for 16-40 years. Regarding the proportion of CPT/GBV clients seen by these clinicians, this varied from 10$19 \%$ of their workload/or all clients_they saw (i.e. 2 clinicians), with a significant number (i.e. 9 clinicians) working almost exclusively ( $80-100 \%$ of their workload), in this area. A further 7 participants had $40-79 \%$ of their caseload in this field. The three remaining clinicians reported having between $20-39 \%$ of clients with CPT/GBV issues. All clinicians worked in the NHS, with most having some experience of also working in either voluntary organizations or the private sector. The frequency of supervision varied between fortnightly (9 interviewees) with 12 meeting at approximately monthly intervals.

\section{Procedure and design}

Face to face qualitative interviews, were used in order to collect the data required. Since IPA is particularly suitable when exploring how participants perceive and make sense of their world, with no attempt to test out a predetermined theory (Smith, 2004; Smith and Osborn, 2007), it was important to construct the interview schedule in such a way that the questions were open ended, while utilising a non-directive interview style (Brocki \& Weardon, 2006). 
The goal was to generate data in order to answer the research question (Willig, 2008), while not imposing preconceived theories or expectations on the interviewees. As it is necessary to have a verbatim account of the data collection event (Willig, 2008; Smith et al., 2013) in order undertake a full analysis of the data, the interviews were recorded and transcribed verbatim. Transcripts were read repeatedly and then coded to identify emergent themes. Recurrent themes were then identified across transcripts. Such themes reflected shared understandings by participants of the issues under investigation. Data were compared and analysed until we were satisfied that emerging themes adequately described the text and that final themes closely reflected the data, i.e. until saturation is reached (O'Callaghan, 2001). To ensure rigour a cohort of the transcripts was read by two researchers in the project team (AMC and ZC) and recurrent themes were discussed in the team (AMC, ZC and KC). The involvement of all team members in this process ensured that the interpretive processes was collaborative and insightful. The data was then analysed further in order to unpack the situated nature of the themes, to understand them fully, and to highlight the similarities and differences in the various participants' accounts (Lofland \& Lofland 1995). Links between emergent themes were also identified and modelled to provide a clinically meaningful framework embedded in the experiences of participants.

\section{Ethics}

Ethical approval was gained from a higher education institution in the west of Scotland. National Health Service (NHS) Research \& Development (R \& D) approvals were not required, because the study involved professionals who are already working with this population in their professional capacity and role.

\section{Analysis}


Recorded interviews of the dialogue were transcribed, with gaps in the discussion recorded, and notes made of any interruptions or difficulty. Although the stages of analysis are listed separately below, it is important to note the cyclical aspect of this process, involving the rereading and re-examining the transcriptions, part of the iterative nature of IPA research (Smith et al., 2013). Following a reading of the first case, notes were made (stage 1) with comments written in the left margin. These included summaries, associations, connections, and preliminary interpretations. Emerging themes were then documented in the right margin of the transcription (stage 2) in order to capture something of the concepts identified before the next level of interpretation which involved listing the emergent themes into theme clusters (stage 3), having identified connections between them. These emerging themes, clustered together into super ordinate themes and made up of subordinate themes, were then used (stage 4) to create a table of themes. Care was taken to ensure that each theme was represented by data in the transcript to avoid researcher bias. This use of "abstraction", identifying patterns between emerging themes to develop super ordinate themes, putting like with like and identifying a new name for the cluster (Smith et al., 2013) played a crucial role in the analytic process. This next phase of the analysis and interpretation (stage 5) involved continuing with other cases, starting with the master themes from case 1 (the transcription from interview 1) and looking for further evidence in case 2, while being ready for new themes to emerge. This cyclical process, requiring the researcher to go back to case 1 to see if new themes are represented there too, re-reading the transcripts, and rethinking the clusters, (looking for convergence and divergence), was essential in order to produce the final Master table of themes.

A framework has been developed by modelling the themes identified in the experiences of therapists working in the field of CPT Clinician-Led Framework of Expansion \& Growth in Trauma Work (Figure 1). 
Qualitative modelling was conducted by utilising a method developed by Zoë Chouliara, consisting of thematic analysis and synthesising of already identified themes, i.e. thematically analysing already extracted themes and subthemes, treating them as original data, and identifying links and meta-themes emerging. It was then possible to create metathemes which captured patterns of connections between themes. These reflected a dialogue process and consensus reached in the research team. This method has been successfully developed and utilised in our previous work (Chouliara \& Kearney, 2007; Chouliara et al., 2004; 2011; 2013; 2017; Chouliara \& Narang, 2017).

\section{Rigour/Validity}

IPA utilises many of the principles of generic qualitative good practice, which it is suggested are quality markers in qualitative research (Elliott et al., 1999), assisting in the production of robust and reflexive research, and increasing the likelihood of publication in professional journals (Reid et al., 2005). Within this study, the use of team consensus (whereby agreement was reached on the themes identified) the maintenance of field notes, and the keeping of a researcher's diary were implemented in order to aid the reflexive process and to minimise the subjective aspect of the interpretation. In addition, a negative case analysis was identified, where the data analysed was found to be inconsistent with the themes, which is also thought to provide evidence for the validity of the work (Creswell \& Miller, 2000). Furthermore, the role of the external observer, (the supervisor) was particularly helpful in order to provide both an understanding of the project together with an overview of the work which was as free as possible from researcher bias.

\section{Results}


The clincians' process was captured by the following themes which describe the profound impact of CPT work.

Called to the Work. Therapists frequently spoke of CPT being a calling or vocation. Some talked of being drawn to this work.

I feel the intensity of it, of what's coming up or what's happened, what we are working through, but I don't...I don't shy away from it, the word enjoy is coming up for me and it's not quite the right thing, it's not what I want to say, I feel it is more a kind of...it's kind of like a vocation really em...it's like em...child abuse, it is everyone's right to do something about that; everyone should be. (M211S 6/7.132-141)

There was a sense that they had already reflected on their role and that helping others in this meaningful way was an integral part of their own life journey.

I think that just through my own personal journey, an understanding of myself and homophobia and hetero-sexism I started to become interested in equality issues and then I started to look at that professionally. I started to understand about how inequality impacted on lots of different people in lots of different ways and how there can be layers of inequalities for people and I was just always really interested in that and fighting stigma. .... then through becoming a counsellor I felt that here I could actually do something to support people........ who had been hurt in some way because of who they were (sexual orientation) or what had happened to them. (M11S 3.63-77) 
Connection, Separation and Oneness. Clinicians described the process of engaging and disengaging in a therapeutic relationship with clients, their sense of clients as 'the other' or 'them', and also how they use themselves (and their own experience of trauma and emotional pain) in this work.

I guess there is a relationship built and (as) they (clients) began to trust more and felt supported they would then go into some of the graphic detail of maybe one of the incidents. I can remember the first time - one of the first times that I thought (that), I was sitting and I came back to my own chair and thought I am so overwhelmed by this story, I was really touched by it, which was a bit scary for me and I thought "oh no this is not what I am supposed to be doing!" (M61S 3.67-4)

Into and out of the darkness. Therapists talked of developing both an awareness of and sensitivity to a darker side of life through this work, which caused them to view the world (and the adults and children within it) differently. This sense of seeing the world differently was frequently mentioned, with participants questioning the motivations of those, (men in particular) who choose to spend time with young children.

I was either still in placement or a volunteer so maybe about three years ago, and I can remember looking at children quite differently; looking at children as really vulnerable and that had a big impact on me because again I had to think not everybody in the world is bad and not every child is going to be sexually abuse. (M131S 6.163-166) 
This sense of seeing the world differently was frequently mentioned, with participants questioning the motivations of those, (men in particular) who choose to spend time with young children.

A close friend of mine met someone new and she had children and her relationship started to crumble- I had thoughts initially about both - not fleeting thoughts but those thoughts that come into your mind about what is this person's (new partner's) motivation and behaviours - there was no reason to feel...to be worried mmm about these children but I think things like that can impact on you. (M91S 8.208-214)

Chaos into Meaning. Many of the clinicians described being part of the client's journey to recover from $\mathrm{CPT}$, on occasion as merely an observer witnessing the process, but more often as a facilitator effecting change. Therapists suggested that there was a process occurring, whereby they had a role in making sense of the often-chaotic stories presented to them, in order not only to create a narrative, but to further develop the meaning of the abuse in the client's sense of themselves, and in their level of understanding of their life journey.

I help clients through the time zones, the past- where it comes from, (and) the presenthow it's affecting them now and what they want to change. (M21S 7.163-165)

This process of meaning making or of putting pieces of a jigsaw together was frequently mentioned.

For me there's a missing piece of the puzzle and the missing piece of the puzzle I think it is in psychological way- ......I thought that there was the only (one) missing piece 
now I realise that there are lots of pieces that have to work together...... in homelessness services, I know that $90 \%$ of people have experienced complex trauma and that is a really high percentage and therefore taking into account somebody's complex PTSD picture needs to be done before or alongside moving people into accommodation. (M81S 2.42-50)

Reparation not Repetition. Clinicians frequently spoke of their desire to redress the balance when considering the unfairness of the trauma that their clients had experienced. In terms of the desire to right the wrong done to clients, therapists suggested that this was not only the unfairness of having been a victim of CPT, but on occasions that their client's distress had been compounded by a lack of understanding or respect, or even by a perceived degree of resentment from professionals and services. Participants suggested that this unreceptive stance could then (together with the broader organisational issues) become a barrier to clients wishing to access services. Therapists highlighted an awareness of systemic problems which can obstruct the clients' pathway into therapy, and the unfairness of victims of CPT suffering once more, as a result of society's attitudes to sexual and childhood abuse, and they spoke of wanting to make reparation.

The system is too large, it doesn't always have the patient in mind, simple things like getting rooms; getting the same room every week; the fact that you may have 6 people who might answer the phone. ......... you need eyes at the back of your head to make sure things work better for patients and that when the patient needs contact then they will know how (to get it), in some way. All the difficulties are when the lack of pathways developed to carry somebody from A to B through the system- and that's a 
function of having teams that are too large (that) I am anxious about. (M41S12.301315)

Clinician Expansion \& Growth, Personal and Professional. Clinicians spoke of how they felt that they had expanded, grown, and developed through this work. Some described this work as giving their own life meaning and of developing a sense of fulfilment as a result.

I think I have developed on different levels but the simplest level it would be having more time and experience, working within the area of complex trauma has helped me to understand about how complex trauma affects people, so my knowledge has improved I think em... I have developed skills to help me assist people to manage those symptoms that are linked to the complex trauma so practical stuff and ....I am most aware of the interpersonal dynamic so I guess that is an increased awareness of that and how powerful that can be .......I I think that is a good thing certainly for me as a therapist. (M151S 10/11.254-271)

Interviewees also described benefits on a personal level, obtaining a greater level of pleasure and even contentment. Therapists highlighted improved clinical skills and an increased sensitivity to the interpersonal (therapeutic) relationship in particular, as occurring through this work, leading to overall professional progression. Others described deeper, more personal consequences.

In this work regarding post traumatic growth, I would see that as I have gone through the stages of this work in the past, any shit that I have gone through personally, and thinking "oh my God what will I do", then thinking "I will do everything". And there 
are some people, a few patients that I can think of, and do you know what actually, they have coped with much worse......... So actually I think that I do feel very confident about that, that I know that I have really helped people, and that's really important - knowing what I can and cannot do. And that's really empowering too, the sense that you have got to a stage in life to be able to help like this. (M111S 10/11.238-249)

\section{Figure 1. Clinician-Led Framework of Expansion \&Growth in Trauma Work-}

Figure 1

\section{Clinician Led Framework of Expansion \&Growth in Trauma Work}

Qualitative modelling was conducted by conducting thematic analysis and synthesising of already identified themes via IPA methodology, i.e. thematically analysing already extracted themes and subthemes, treating them as original data, and identifying links and meta-themes emerging. That way we were able to create meta-themes which captured patterns of connections between themes. These reflected a dialogue process and consensus in the research team. This method was developed in previous published work specifically in the area of complex trauma/childhood sexual abuse (Chouliara et al., 2004; 2011; 2013; 2017; Chouliara \& Narang, 2017). A more detailed description of this qualitative modelling method is beyond the scope of this paper and will be published elsewhere.

Through this analysis, it became apparent that what was in the centre of all accounts, as a common thread, was a dynamic process of expansion and growth through this type of work. As a result, we engaged in a process of modelling our themes around this key central idea in 
order to develop this framework, and identified key milestones, that clinicians have to go through in order to facilitate this process. These milestones include: clinicians being in touch with and re-evaluating their motivation to this work; maintaining good therapeutic relationships in fragile process; building capacity to tolerate all aspects of human nature, including the darker ones; maintaining capacity to self-reflect on a personal and professional level in order to contain distress and maximise healing processes. The framework captures the movement in this deep, interactive process of change and growth, and also emphasises the relational aspects in this growth process.

\section{Discussion}

The findings in this study provide a clinically applicable framework, embedded in the clinician's experience of engagement in CPT work. The findings and proposed framework draws attention to the complexity of impacts for professionals. It highlights the potentially detrimental effects of working with survivors of traumas, as well as impacts that relate to resilience, connectedness and growth. The data strongly pointed at a growing at a personal and professional level through this process of the giving of themselves to others (CPT survivors). There seemed to be something quite profound, about being in an intimate, albeit professional therapeutic relationship with this specific client group. In particular, bearing witness to the traumas which clients had endured, in contrast to the resilience and stoicism displayed in the therapy room, appears to have had a wider positive impact on clinicians, regarding their sense of themselves and in their confidence in personal and professional relationships.

Contextualising Findings within Previous Research and Policy 
Our findings propose a new extended understanding of the relational way in which clinicians engage with this client group and the how this interactive process brings benefits not only to clients, in terms of their recovery, but also to clinicians themselves through the experience of Vicarious Post Traumatic Growth. Although since early stages of research in the field of trauma focussed work there has been the possibility that the impact on clinicians was not entirely negative (Pearlman L.A \& MacIan 1995: Hudnell Stamm, B.H. 1998: Guhan, R.\& Leibling-Kalifani, H. 2011), there has been a widely held belief that the work is inherently damaging (McCann, I. L. \& Pearlman, L.A. 1990: Neumann, D.A. \& Gamble 1995: Schauben, L.J.,\& Frazier P.A. 1995: Smith et al 2007). This research therefore appears to sit out with these findings and to present new insight not only into the possibility of positive gains from the CPT work, but also provides a deeper and more wholesome understanding of the meaning therapists assign to their experience of working with highly traumatised clients. Research suggesting that there may be positive outcomes for clinicians (Barrington, A.L. \& Shakespeare Finch, J. 2013: Weaver, M., and Biggart, 2012; Brockhouse, et al 2011), including a level of growth or resilience, is limited and has often related to trauma generally and CPT. It has less often been focussed on those who work in the specialist area of GBV and CSA complex trauma. However, there is some connection with the findings of Samios et al., (2013) and Samios et al., (2012) who have identified a level of growth for clinicians or positive outcomes. To our knowledge, there is no precedence in the literature of a framework in which the experience of clinicians and their level of meaning making (occurring within this fluid, dynamic and interactive encounter), as the one proposed here. The work of Hobfoll et al., (2007) although not focused on clinicians, might be of some relevance here in support of this framework. Hobfoll and colleagues (2007) found positive associations between posttraumatic growth and post-traumatic stress. They have also suggested that post-traumatic growth is more helpful and functional if action - based and not a simple re-interpretation of 
traumatic events. Clinical training enhances awareness, mindful reflection, and empathy; therefore, clinicians might become both more aware of their own distress, but also of their motives to help others.

Another distinctive aspect of our findings is the relational way that clinicians described the positive and negative impacts of their work in the complex trauma field. This highlights the greater need for the application of relational models in this field more than in other fields of practice. The link between empathy and negative impact of such work, such as compassion fatigue and burnout, has been controversial. Recent evidence by Turgoose et al. (2017) supports an association between high levels of dispositional empathy and low levels of compassion fatigue in a sample of police officers in Scotland. Thus, the role of empathy as a protective factor is advocated. Although this research was in the area of sexual assault, it did not utilise a sample of clinicians. Furthermore, the participants had not been working for too long in this area which can explain their low levels of compassion fatigue overall. Nevertheless, empathy in the therapeutic relationship is a key factor of change within relational models. In addition, empathy's links with trust and recovery from complex trauma (Chouliara et al., 2013; Chouliara et al., 2017; Chouliara \& Narnag, 2017), provide further support for more relational approaches both in practice, but also in self-care and consultative support.

Guidelines and systematic reviews regarding post-traumatic stress disorder (PTSD) have been available for some time by the National Institute for Health and Clinical Excellence (NICE 2013). However, there are currently no NICE guidelines for the treatment of CPTSD and -more importantly- there no NICE guidelines for protecting clinicians of the impact of this work or self care in this field of practice. The present findings highlight the need for the development of NICE and SIGN (Scottish Intercollegiate Guidelines Network) guidelines for good practice for those working clinically or planning services in this field 
(UKPTS 2016). Therefore, the findings of this research, with a new understanding of how clinicians engage in and may benefit from the work is likely to be of value when reviewing the role of health workers, and their engagement with severely traumatised individuals and also for the safeguarding and delivery of services. Such guidelines would be paramount in prevention of detrimental impacts and promoting self care, resilience and growth in clinicians working in this field. Regarding policy frameworks within Scotland, the Scottish Government/NHS Education for Scotland 'Transforming Psychological Trauma: A Skills and Knowledge Framework for The Scottish Workforce' also highlights the importance of improved training and awareness for health professionals, management, organisations and education providers in order to provide a 'trauma informed workforce'. (SG/NES 2017). Nevertheless, even this framework does not touch upon the risks of vicarious traumatisation and the need for self care, growth and personal development of the workforce in this field. Given that we live in an increasingly traumatogenic world, due to war/conflict, movement of populations, and extreme weather conditions, it is expected that professionals and services will be increasingly called worldwide to called to respond to individuals and groups suffering from (complex) psychological trauma. The need therefore arises for a workforce who is trauma-sensitive, trauma aware and trauma-focused, but also for a worldwide framework for good practice and self care. The present findings advocate therefore the development of such framework potentially via the World Health organisation (WHO) and for imbedding such in the official curriculum and service delivery internationally with a particular focus in countries afflicted more by high level of conflict, migration, war and human rights violations.

\section{Strengths and Limitations}

Since the research was carried out within NHS services with specialist and highly qualified therapists, working within well-defined parameters, the results may have been quite different 
if participants were from other backgrounds. In addition, having taken place within Scotland it may not be possible to generalise the findings to other parts of the UK or indeed elsewhere. However, even with these unavoidable limitations, the study provides a starting point for further discussion about the role of GBV/CSA therapists, the impact of the work on clinicians (in terms of personal and professional development), and the meaning they make of this complex and demanding work.

\section{Suggestions for practice and research}

The present findings have highlighted positive aspects of working in this field, which point towards a growth mindset. These will need to be unpicked by following research. Understanding all aspects of the experience of working in this field is paramount in raining, selection and safeguarding. Positive aspects are also important in retention and welfare of the workforce. The provision of good practice guidelines for facilitating growth while working in CPT may help to prevent burnout and could offer a containing framework, supporting therapists in this challenging work. More specialised training in this area is likely to be helpful to increase knowledge and practitioner confidence, both at an academic prequalification level and in terms of Continuing Professional Development (CPD). Based on our findings, the provision of supervisee led supervision, rather than a case/line management model (with a heavier focus on service goals), is likely to offer a more supportive environment for clinicians by facilitating a more open exploration of client work and impacts. In term of service delivery and policy, by providing therapy for CPT within a wider context of trauma informed care, as suggested by Bassuk et al., (2016) clinicians can plan more effective services for those experiencing CPT (or Complex PTSD) and increase the awareness of those workers out with specialist services. Our findings are very conducive to trauma informed approaches. This is because trauma informed approaches Realize the 
widespread impact of trauma and understands potential paths for recovery; Recognize the signs and symptoms of trauma in clients, families, staff, and others involved with the system; Respond by fully integrating knowledge about trauma into policies, procedures, and practices; and Seek to actively resist re-traumatization. One of the strengths of traumainformed approaches can be implemented in any type of service setting or organization and is distinct from trauma-specific interventions or treatments that are designed specifically to address the consequences of trauma and to facilitate healing. A trauma-informed approach reflects adherence to six key principles rather than a prescribed set of practices or procedures. These principles may be generalizable across multiple types of settings and include: Safety; Trustworthiness and Transparency; Peer support; Collaboration and mutuality; Empowerment, voice and choice; Cultural, Historical, and Gender Issues (Center for Mental Health Services, Update, 2008). Our findings are not dissimilar to the trauma informed models in acknowledging the potential impact on the workforce and also the opportunity for growth and thriving beyond surviving such impact. Our findings could contribute to and expand the evidence base of such models in terms of peer support, empowerment and thriving of clinicians. The proposed framework can be translated in strategies to aid meaning making and self care as part of such approaches.

In this study we did not focus on self care and participants did not specifically disclose their own self care strategies. It might be useful that future research unpicks specific distortions and ruptures in clinicians as well as the clinicians' self care practices, in order to suggest practices for recovery and prevention and aid growth. Further research undertaken in a wider sample of clinicians from all sector, including, the NHS at Primary Care level (instead of specialist services), voluntary agencies, and independent sectors, would provide an opportunity to investigate the applicability and generalisability of these findings. 


\section{Conclusion}

The findings of this highlight the need to supply a robust professional, well trained, supervised body of clinicians to meet the potentially increasing needs of traumatised individuals worldwide. It is hoped that by highlighting the value of specialist training, sensitive recruitment policies, appropriate supervision, and good practice guidelines for self care, we can safeguard not only the welfare of the workforce but also the wellbeing of these vulnerable client group too. This is likely therefore to aid the retention of staff and facilitate better satisfaction and engagement with services. This line of work can be rewarding and growth based for clinicians if they the challenges of this work are well managed on a personal and organisational level nationally and international at all levels of training, practice and supervision.

\section{Acknowledgements}

We would wish to thank all participants who gave generously of their time and the services who agreed to be involved.

\section{Declaration of Conflicting Interests}

The authors declared no potential conflicts of interest with respect to this research, authorship, and/ or publication of this article.

\section{Funding}

This study has not been in receipt of financial support. 
Adams, R. E., Boscarino, J. A., \& Figley, C. R. (2006). Compassion fatigue and psychological distress among social workers: a validation study. American Journal of orthopsychiatry, 76(1), 103.

Amnesty International. (2016). Tackling the global refugee crisis from shirking to sharing responsibility. https://www.amnesty.org.uk/cse/search/refugee $\% 20$ statistics accessed 27/02/17.

Amnesty International. (2014) Amnesty International. 2014, Human Rights [online].

Available at: http://www.amnesty.org/en/human-rights. [Accessed 20th November 2014].

Baird, K., \& Kracen, A. C. (2006). Vicarious traumatization and secondary traumatic stress: A research synthesis*. Counselling Psychology Quarterly, 19(2), 181-188.

Barrington, A.J. \& Shakespeare-Finch, J. (2013). Working with refugee survivors of torture and trauma: An opportunity for vicarious post-traumatic growth. Counselling Psychology Quarterly,26 (1), 89-105.

Benjet, C., Bromet, E., Karam, E. G., Kessler, R. C., McLaughlin, K. A., Ruscio, A. M., ... \& Alonso, J. (2016). The epidemiology of traumatic event exposure worldwide: results from the World Mental Health Survey Consortium. Psychological medicine, 46(2), 327-343.

Bassuk, E. L., Unick, G. J., Paquette, K., \& Richard, M. K. (2017). Developing an instrument to measure organizational trauma-informed care in human services: The TICOMETER. Psychology of violence, 7(1), 150.

Breslau, N., Kessler, R. C., Chilcoat, H. D., Schultz, L. R., Davis, G. C., \& Andreski, P. (1998). Trauma and posttraumatic stress disorder in the community: the 1996 Detroit Area Survey of Trauma. Archives of general psychiatry, 55(7), 626-632.

Bride, B. E. (2007). Prevalence of secondary traumatic stress among social workers. Social work, 52(1), 63-70.

Brockhouse, R., Msetfi, R. M., Cohen, K., \& Joseph, S. (2011). Vicarious exposure to trauma and growth in therapists: The moderating effects of sense of coherence, organizational support, and empathy. Journal of Traumatic Stress, 24(6), 735-742.

Brocki, J. M., \& Wearden, A. J. (2006). A critical evaluation of the use of interpretative phenomenological analysis (IPA) in health psychology. Psychology and health, 21(1), 87108.

Canfield, J. (2005). Secondary traumatization, burnout, and vicarious traumatization: A review of the literature as it relates to therapists who treat trauma. Smith College Studies in Social Work, 75(2), 81-101.

Chouliara, Z., \& Javita, N. (2017). Recovery from child sexual abuse (CSA) in India: A relational framework for practice. Children and Youth Services Review. doi:org/10.1016/j.childyouth.2017.06.072

Chouliara, Z., Karatzias, T., Gullone, A., Ferguson, S., Cosgrove, K., \& Burke Draucker, C. (2017). Therapeutic Change in Group Therapy For Interpersonal Trauma: A Relational Framework for Research and Clinical Practice. Journal of Interpersonal Violence, 0886260517696860.

Chouliara, Z., Karatzias, T., \& Gullone, A. (2014). Recovering from childhood sexual abuse: A theoretical framework for practice and research. Journal of psychiatric and mental health nursing, 21(1), 69-78. doi: 10.1111/jpm.12048

Chouliara, Z., Karatzias, T., Gullone, A., Ferguson, S. \& Cosgrove, K. (2013) Therapeutic change from interpersonal trauma in group work: A framework for research and clinical practice, Edinburgh Napier University, Scotland. 
Chouliara, Z., Karatzias, T., Scott-Brien, G., Macdonald, A., MacArthur, J., \& Frazer, N. (2012). Adult survivors of childhood sexual abuse perspectives of services: A systematic review. Counselling and Psychotherapy Research, 12(2), 146-161. doi:10.1080/14733145.2012.656136

Chouliara, Z., Karatzias, T., Scott-Brien, G., Macdonald, A., MacArthur, J., \& Frazer, N. (2011). Talking therapy services for adult survivors of childhood sexual abuse (CSA) in Scotland: Perspectives of service users and professionals. Journal of child sexual abuse, 20(2), 128-156.

Chouliara, Z., Hutchison, C., \& Karatzias, T. (2009). Vicarious traumatisation in practitioners who work with adult survivors of sexual violence and child sexual abuse: Literature review and directions for future research. Counselling and Psychotherapy Research, 9(1), 47-56.

Chouliara, Z., \& Kearney, N. (2007). Working with older people with cancer: challenges in research and clinical practice. In F. Anagnostopoulos \& E. Karadimas (Eds), Special issues in health psychology (pp. 131-151), Athens, Greece: Livani Publishers.

Chouliara, Z., Kearney, N., Stott, D., Molassiotis, A., \& Miller, M. (2004). Perceptions of older people with cancer of information, decision making and treatment: a systematic review of selected literature. Annals of Oncology, 15(11), 1596-1602.

Chouliara, Z \& Narang, J (2017) Recovery from child sexual abuse (CSA) in India: A relational framework for practice. Children \& Youth Services Research. In Press (https://doi.org/10.1016/j.childyouth.2017.06.072)

Cloitre, M.; Garvert, D. W.; Brewin, C. R.; Bryant, R.A.; Maercker, A. (2013). Evidence for proposed ICD-11 PTSD and complex PTSD: A latent profile analysis. European Journal of Psychotraumatology, 4, 1-12.

Cook, J. M., Dinnen, S., Rehman, O., Bufka, L., \& Courtois, C. (2011). Responses of a sample of practicing psychologists to questions about clinical work with trauma and interest in specialized training. Psychological Trauma: Theory, Research, Practice, and Policy, 3(3), 253.

Courtois, C. A., \& Ford, J. D. (Eds.). (2009). Treating complex traumatic stress disorders: An evidence-based guide. Guilford Press.

Creswell, J. W., \& Miller, D. L. (2000). Determining validity in qualitative inquiry. Theory into practice, 39(3), 124-130.

Elliott, R., Fischer, C. T., \& Rennie, D. L. (1999). Evolving guidelines for publication of qualitative research studies in psychology and related fields. British journal of clinical psychology, 38(3), 215-229.

Europol (2017) EU Terrorism Report: 142 failed, foiled and completed attacks.

https://www.europol.europa.eu/.../2017-eu-terrorism-report-142-failed-foiled-and-co...

Accessed 24/08/17.

Fang, X., Fry, D.A., Ji, K., Finkelhor, D., Chen, J., Lannen, P. and Dunne, M.P., 2015. The burden of child maltreatment in China: a systematic review. Bulletin of the World Health Organization, 93(3), pp.176-185C.

Figley, C. R. (Ed.). (2002). Treating compassion fatigue. Routledge.

Figley, C. R. (2002). Compassion fatigue: Psychotherapists' chronic lack of self-care. Journal of clinical psychology, 58(11), 1433-1441.

Finlay, L., \& Ballinger, C. (Eds.). (2006). Qualitative research for allied health professionals: Challenging choices. John Wiley \& Sons.

Ford, JD; Hawke, J; Alessi, S; Ledgerwood, D; NPetry N (2007). Psychological trauma and PTSD symptoms as predictors of substance dependence treatment outcomes. Behavior, Research \& Therapy, 45 (10), 2417-31 - DOI: 10.1016/j.brat.2007.04.001 
Frenken, J., \& Van Stolk, B. (1990). Incest victims: Inadequate help by professionals. Child abuse \& neglect, 14(2), 253-263.

Guhan, R., \& Liebling-Kalifani, H. (2011). The experiences of staff working with refugees and asylum seekers in the United Kingdom: A grounded theory exploration. Journal of Immigrant \& Refugee Studies, 9(3), 205-228.

Herman, J. L. (1992a). Trauma and recovery. New York: Basic Books.

Herman, J. L. (1992). (1992a). Complex PTSD: A syndrome of survivors of prolonged and repeated trauma. Journal of Traumatic Stress, 5, 377-391.doi:10.1007/BF00977235

Hernández, P., Gangsei, D., \& Engstrom, D. (2007). Vicarious resilience: A new concept in work with those who survive trauma. Family process, 46(2), 229-241.

Hobfoll, SE and Hall, BJ; Canetti-Nisim, D; Galea, S;. Johnson, RJ Patrick Palmieri, A (2007). Refining our Understanding of Traumatic Growth in the Face of Terrorism: Moving from Meaning Cognitions to Doing what is Meaningful. Applied Psychology: An International Review, 56 (3), 345-366 doi: 10.1111/j.1464-0597.2007.00292

Horvath, A. O., \& Symonds, B. D. (1991). Relation between working alliance and outcome in psychotherapy: A meta-analysis.

Hinton, D. E., \& Lewis-Fernández, R. (2011). The cross-cultural validity of posttraumatic stress disorder: implications for DSM-5. Depression and anxiety, 28(9), 783-801.

Hudnell Stamm B.H. 1998, Rural-Care: Crossroads of Health Care, Culture, Traumatic Stress Technology [online]. Available at:http://www.isu.edu/bhstamm/index.htm [Accessed 1st July 2007].

Karatzias, T., Shevlin, M., Fyvie, C., Hyland, P., Efthymiadou, E., Wilson, D., ... \& Cloitre, M. (2016). An initial psychometric assessment of an ICD-11 based measure of PTSD and complex PTSD (ICD-TQ): Evidence of construct validity. Journal of anxiety disorders, 44, 73-79.

Karatzias, T., Shevlin, M., Fyvie, C., Hyland, P., Efthymiadou, E., Wilson, D., ... \& Cloitre, M. (2017). Evidence of distinct profiles of posttraumatic stress disorder (PTSD) and complex posttraumatic stress disorder (CPTSD) based on the new ICD-11 trauma questionnaire (ICD-TQ). Journal of affective disorders, 207, 181-187.

Kessler, R. C., Sonnega, A., Bromet, E., Hughes, M., \& Nelson, C. B. (1995). Posttraumatic stress disorder in the National Comorbidity Survey. Archives of general psychiatry, 52(12), 1048-1060.

Lofland, J. and Lofland, L. H. (1995). Analyzing Social Settings: A Guide to Qualitative Observation and Analysis ( $3^{\text {rd }}$ Editi on). Belmont, CA: Wadsworth.

McCann, I. L., \& Pearlman, L. A. (1990). Psychological trauma and the adult survivor: Theory, therapy, and transformation (No. 21). Psychology Press.

McCann, I L., \&Pearlman, L. A. (1990). Vicarious traumatization: A framework for understanding the psychological effects of working with victims. Journal of traumatic stress, 3(1), 131-149.

Morina, N., \& Ford, J. D. (2008). Complex sequelae of psychological trauma among Kosovar civilian war victims. International Journal of Social Psychiatry, 54(5), 425-436.

Moore, S.E., Scott, J.G., Ferrari, A.J., Mills, R., Dunne, M.P., Erskine, H.E., Devries, K.M., Degenhardt, L., Vos, T., Whiteford, H.A. and McCarthy, M., 2015. Burden attributable to child maltreatment in Australia. Child abuse \& neglect, 48, pp.208-220.

National Institute for Clinical Excellence. (2013). Evidence update: The management of PTSD in adults and children in primary and secondary care. Wilshire, United Kingdom: Cromwell Press

Neumann, D. A., \& Gamble, S. J. (1995). Issues in the professional development of psychotherapists: Countertransference and vicarious traumatization in the new trauma therapist. Psychotherapy: Theory, research, practice, training, 32(2), 341. 
Norris, F.H. \& Sloane, L.B. 2007, The Epidemiology of trauma and PTSD. in: Handbook of PTSD: Science and Practice, eds. M.J. Friedman, T.M. Keane \& P.A. Resick, The Guilford Press, New York, pp. 78-98.

NSPCC Knowledge and Information Services 2017 Child protection register and plan $\begin{array}{lllll}\text { statistics for all nK } & \text { nations }\end{array}$ https://www.nspcc.org.uk/globalassets/documents/statistics-and-information/childprotection-register-statistics-united-kingdom.pdf

NSPCC Saied- Tessier 2014. Estimating the costs of child sexual abuse in the UK

https://www.nspcc.org.uk/globalassets/.../estimating-costs-child-sexual-abuse-uk.pdf

O'Callaghan, C \& Hiscock, R (2007). Interpretive subgroup analysis extends modified grounded theory research findings in oncologic music therapy. Journal of Music Therapy, 44(3), 256-281.

Ogle, C. M., Rubin, D. C., \& Siegler, I. C. (2014). Cumulative exposure to traumatic events in older adults. Aging \& mental health, 18(3), 316-325.

Pearlman, L. A., \& MacIan, P. S. (1995). Vicarious traumatization: An empirical study of the effects of trauma work on trauma therapists. Professional Psychology: Research and Practice, 26(6), 558.

Pringle, J., Drummond, J., McLafferty, E., \& Hendry, C. (2011). Interpretative phenomenological analysis: a discussion and critique. Nurse researcher, 18(3), 20-24.

Ray, S. L. (2008). Evolution of posttraumatic stress disorder and future directions. Archives of Psychiatric Nursing, 22(4), 217-225.

Reid, K., Flowers, P. \& Larkin, M. 2005, Exploring lived experience, The Psychologist, 18(1), 20-23.

Resick, P. A., Bovin, M. J., Calloway, A. L., Dick, A. M., King, M. W., Mitchell, K. S., ... \& Wolf, E. J. (2012). A critical evaluation of the complex PTSD literature: Implications for DSM-5. Journal of traumatic stress, 25(3), 241-251.

Roberts, A. L., Gilman, S. E., Breslau, J., Breslau, N., \& Koenen, K. C. (2011). Race/ethnic differences in exposure to traumatic events, development of post-traumatic stress disorder, and treatment-seeking for post-traumatic stress disorder in the United States. Psychological medicine, 41(1), 71-83.

Robinson-Keilig, R. A. (2014). Secondary traumatic stress and disruptions to interpersonal functioning among mental health therapists. Journal of interpersonal violence, 29(8), 1477-1496.

Samios, C., Abel, L. M., \& Rodzik, A. K. (2013). The protective role of compassion satisfaction for therapists who work with sexual violence survivors: An application of the broaden-and-build theory of positive emotions. Anxiety, Stress \& Coping, 26(6), 610-623.

Samios, C., Rodzik, A. K., \& Abel, L. M. (2012). Secondary traumatic stress and adjustment in therapists who work with sexual violence survivors: The moderating role of posttraumatic growth. British Journal of Guidance \& Counselling, 40(4), 341-356.

SAMHSA 2008. Models for Developing Trauma - Informed Behavioral Health Services Trauma- Specific Service, Update 2008. Center for Mental Health Services, National Centre for Trauma- Informed Care; Funded by Substance Abuse \& Mental Health Services Administration (SAMHSA).

Scottish Government/ NHS Education for Scotland2017National Trauma Training Frameworkhttp://www.nes.scot.nhs.uk/education-and-training/bydiscipline/psychology/multiprofessional-psychology/national-trauma-trainingframework.aspx accessed 20/08/17

Schauben, L. J., \& Frazier, P. A. (1995). Vicarious trauma the effects on female counselors of working with sexual violence survivors. Psychology of women quarterly, 19(1), 49-64. 
Shah, S. A., Garland, E., \& Katz, C. (2007). Secondary traumatic stress: Prevalence in humanitarian aid workers in India. Traumatology, 13(1), 59.

Smith, J. A., Flowers, P. \& Larkin, M. 2013, Interpretative Phenomenological Analysis: Theory, Method and Research, Sage Publications Ltd, London.

Smith, J. A., \& Osborn, M. (2007). Pain as an assault on the self: An interpretative phenomenological analysis of the psychological impact of chronic benign low back pain. Psychology and health, 22(5), 517-534.

Smith, J. A. (2007). Hermeneutics, human sciences and health: Linking theory and practice. International Journal of Qualitative Studies on health and Well-being, 2(1), 3-11.

Smith, A. J., Kleijn, W. C., Trijsburg, R. W., \& Hutschemaekers, G. J. (2007). How therapists cope with clients' traumatic experiences.

Smith, J. A. (2004). Reflecting on the development of interpretative phenomenological analysis and its contribution to qualitative research in psychology. Qualitative research in psychology, 1(1), 39-54.

Spataro, S; Mullen, PE; Burgess, PM; Wells, DL; Moss, SA (2004). Impact of child sexual abuse on mental health. Prospective study in males and females. The British Journal of Psychiatry, 184 (5), 416-421, DOI: 10.1192/bjp.184.5.416.

Splevins, K. A., Cohen, K., Joseph, S., Murray, C., \& Bowley, J. (2010). Vicarious posttraumatic growth among interpreters. Qualitative Health Research, 20(12), 17051716.

Sprang, G., Clark, J. J., \& Whitt-Woosley, A. (2007). Compassion fatigue, compassion satisfaction, and burnout: Factors impacting a professional's quality of life. Journal of Loss and Trauma, 12(3), 259-280.

Staub, E., \& Vollhardt, J. (2008). Altruism born of suffering: the roots of caring and helping after victimization and other trauma. American Journal of Orthopsychiatry, 78(3), 267.

Stein, Jacob Y.; Wilmot, Dayna V.; Solomon, Zahava (2016), "Does one size fit all? Nosological, clinical, and scientific implications of variations in ptsd criterion A", Journal of Anxiety Disorders, 43: 106-117, PMID 27449856, doi:10.1016/j.janxdis.2016.07.001

Stoltenborgh, M., Van Ijzendoorn, M.H., Euser, E.M. and Bakermans-Kranenburg, M.J., (2011). A global perspective on child sexual abuse: Meta-analysis of prevalence around the world. Child maltreatment, 16(2), pp.79-101.

Tedeschi, R. G., \& Calhoun, L. G. (2004). " Posttraumatic growth: Conceptual foundations and empirical evidence". Psychological inquiry, 15(1), 1-18.

Tedeschi, R. G., Park, C. L., \& Calhoun, L. G. (Eds.). (1998). Posttraumatic growth: Positive changes in the aftermath of crisis. Routledge. 1-22, 226.

Teicher MH \& Parigger A (2015). The 'Maltreatment and Abuse Chronology of Exposure' (MACE)

Scale for the retrospective assessment of abuse and neglect during development. PLOS ONE, 10(2):

e0117423. doi:10.1371/journal.pone.0117423

http://journals.plos.org/plosone/article?id=10.1371/journal.pone. 0117423

Turgoose, D; Glover, N; Barker, C; Maddox, L (2017). Empathy, compassion fatigue and burnout in police officers working with rape victims. Traumatology. DOI: $10.1037 /$ trm0000118

United Nations High Commissioner for Refugees. UNHCR (2012) Working with men and boy survivors of sexual and gender-based violence in forced displacement. Geneva:

UKPTS Complex Trauma Guideline (2016). British Psychological Society

www.bps.org.uk/.../ukpts_guideline_for_treating_complex_ptsd_draft_for_external_ accessed 20/08/17

United Nations Refugee Agency UNHCR (2015) Figures at a Glance. http://www.unhcr.org/uk/figures-at-a-glance.html accessed 27/02/17 
United Nations Refugee Agency UNHCR (2017) Figures at a Glance http://www.unhcr.org/uk/figures-at-a-glance.html accessed 26/01/17.

United nations Institute for Training and Research (2013). Help to Alleviate the Global Burden of Trauma. New Responses to a Challenge for Governments, UN agencies and Civil Society

https://www.unitar.org/ptp/help-alleviate-global-burden-trauma-new-responses-challengegovernments-un-agencies-and-civil-societ accessed 10/08/17.

UN Women (2017) http:/www.unwomen.org/en/what-we-do/ending-violence-againstwomen/facts-and-figures accessed 26/01/17

UKPTS Complex Trauma Guideline (2016) British Psychological Society

www.bps.org.uk/.../ukpts_guideline_for_treating_complex_ptsd_draft_for_external_ accessed 20/08/17

Vu, A., Adam, A., Wirtz, A., Pham, K., Rubenstein, L., Glass, N., Singh, S. (2014). The Prevalence of Sexual Violence among Female Refugees in Complex Humanitarian Emergencies: a Systematic Review and Meta-analysis. PLoS Currents, 6, ecurrents.dis.835f10778fd80ae031aac12d3b533ca7. http://doi.org/10.1371/currents.dis.835f10778fd80ae031aac12d3b533ca7

Way, I., VanDeusen, K. M., Martin, G., Applegate, B., \& Jandle, D. (2004). Vicarious trauma: A comparison of clinicians who treat survivors of sexual abuse and sexual offenders. Journal of interpersonal violence, 19(1), 49-71.

Weaver, M. \& Biggart, F. (2012). "Trauma Resilience", Healthcare Counselling and Psychotherapy Journal, Vol. 12, no. 2, 19-23.

World health organization (2013) WHO releases guidance on mental health care after trauma. http://www.who.int/mediacentre/news/releases/2013/trauma mental_health_20130806/en/ accessed 20/08/17.

Willig, C. (2001). Introducing qualitative research in psychology. Open University Press (UK).

Willig, C. (2008). Introducing qualitative research in psychology. $2^{\text {nd }}$ Edn. Open University Press (UK). 
Figure 1

P15

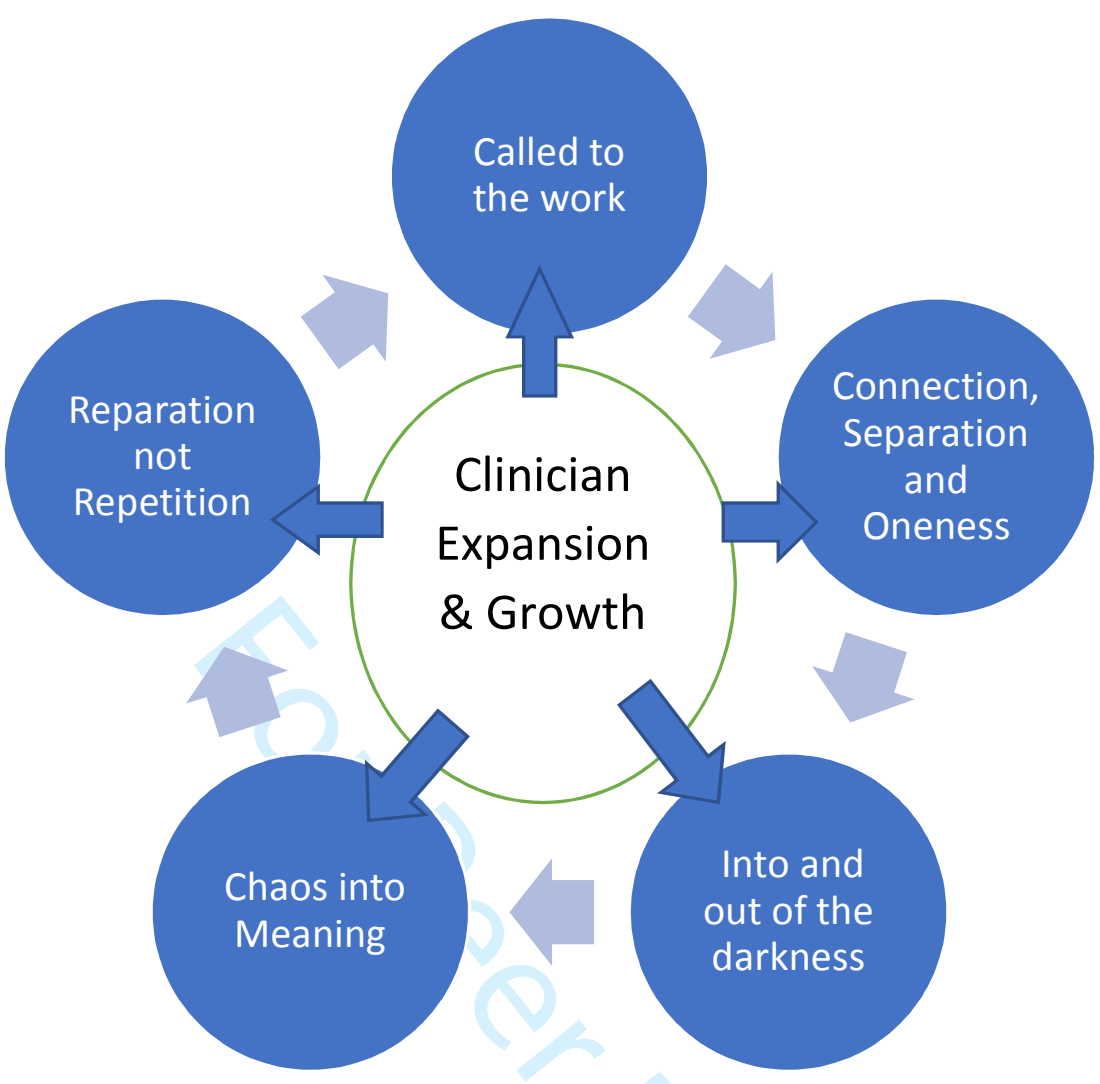

Themes:

Called to the Work: therapists spoke of feeling drawn to working in the field of trauma.

Connection, Separation and Oneness: a sense of being connected to while at times needing to separate from, traumatised clients.

Into and Out of the darkness: entering a disturbing world of abuse and trauma while recognising the importance of being able to leave this dark place.

Chaos into Meaning: engaging with clients to help them make some meaning of the often chaotic relationships and multiple abuses they have experienced.

Reparation Not Repetition: a strong desire to repair past hurt, not to repeat the abuse (particularly within organisations), by not hearing clients or failing to meet their needs.

To summarise, there was a strong sense of a process occurring within the trauma therapy, with the therapist in a central position, engaging and disengaging with the client and with the disturbing material brought to the therapeutic space. 